\title{
ALEGORÍA, EMBLEMÁTICA Y DOCTRINA CRISTIANA EN UN CONVENTO DE CLAUSURA ARAGONÉS DEL SIGLO XVII: UN PROGRAMA PICTÓRICO INSPIRADO EN LA REGIA VIA CRUCIS DE BENEDICTUS VAN HAEFTEN
}

\author{
POR
}

\author{
JOSÉ JAVIER AZANZA LÓPEZ \\ Universidad de Navarra
}

El convento de la Purísima Concepción y San Blas de Miedes (Zaragoza) conserva en su claustro ocho lienzos del último cuarto del siglo xvir, ejecutados con casi toda probabilidad por un pintor de la estimable escuela aragonesa al que no resulta ajeno el conocimiento de la pintura de la Corte. Mas el interés de los lienzos no reside tan sólo en su calidad pictórica; el conjunto compone además un programa iconográfico unitario y desarrolla una interesante catequesis muy propia de la espiritualidad barroca dirigida a las monjas de la comunidad religiosa. El punto de partida de todo ello se encuentra en una de las obras doctrinales más importantes del siglo xVII: la Regia Via Crucis, de Benedictus Van Haeften, cuyos grabados inspiran los lienzos del convento aragonés. Las ocho estampas escogidas para plasmar en lienzo constituyen una síntesis perfecta de la doctrina contenida en la Regia Via Crucis, en el marco de una clausura femenina que conservaba como preciada reliquia una cruz entregada por la Virgen a la madre sor Inés de Jesús y Franco, la cual había obrado milagrosas curaciones.

Palabras clave: Pintura española del s. xviI. Alegoría. Programa Iconográfico de Miedes (Zaragoza).

In the cloister of the convent of the Purísima Concepción y San Blas in Miedes (Zaragoza) there are eight paintings dating from the last quarter of the seventeenth century, in all probability created by an Aragonese artist who was not unfamiliar with painting at Court. The importance of these works rests not only on their pictorial quality but on their unified iconography, in which doctrine imbued with baroque spirituality is directed to the nuns of the religious community. The source can be found in Benedictus Van Haeften's Regia Via Crucis, one of the most significant seventeenth-century doctrinal works. The eight prints chosen as models for the canvases constitute a perfect synthesis of the doctrine contained in the Regia Via Crucis, within the context of a female convent in which a cross given by the Virgin to the mother of sister Inés de Jesús y Franco was preserved as a precious relic and had effected miraculous healings. Convent.

Key words: XVII Century Spanish painting. Allegory. Iconographic Programme. Miedes (Zaragoza)

\section{El convento de Concepcionistas de Miedes (Zaragoza)}

Corría el año 1613 cuando un grupo de seis religiosas concepcionistas se ponía en camino desde Tarazona hasta Miedes para fundar en esta localidad aragonesa un nuevo convento de su 
orden bajo la advocación de la Purísima Concepción y San Blas, atendiendo así una petición de la Comunidad de Calatayud ${ }^{1}$. Pese a que las capitulaciones contemplaban la construcción de convento e iglesia, inicialmente no debió de edificarse sino una parte de las dependencias y oficinas para habitación de las monjas, de manera que durante más de medio siglo los divinos oficios se celebraron en la cercana ermita de San Blas; así se desprende de un memorial que en 1665 dirigía la abadesa sor Inés Francisca Melendo al rey Carlos II, en el que daba cuenta de los avatares y penurias sufridos por la comunidad a lo largo de todo este tiempo. Merced a las disposiciones del monarca, un año más tarde los maestros de obras Diego de Mendoça y José Gassen Aznar, vecinos de Calatayud y Zaragoza respectivamente, contrataban la ejecución de la iglesia conventual de planta de cruz latina, con sus coros alto y bajo, torre de tres cuerpos y portada principal, todo lo cual debía quedar finalizado para el mes de agosto de $1670^{2}$.

Solventadas diversas dificultades que sobrevinieron a lo largo del proceso constructivo, la bendición de la iglesia y traslación del Santísimo Sacramento y de las reliquias de San Alejandro Mártir - cuyo cuerpo había sido enviado desde Roma por el padre Francisco Franco de la Compañía de Jesús - tuvo lugar el 26 de noviembre de 1674. Casi dos siglos después, en 1857, el edificio conventual amenazaba con venirse abajo, por lo que se hizo necesaria una completa reparación llevada a cabo por el maestro de obras Simón Longares, a la que siguió otra menor en 1860 por José Cabello ${ }^{3}$. Ya en 1994 la iglesia recibió una nueva remodelación fruto de la cual es su estado actual ${ }^{4}$.

\section{Los ocho lienzos del claustro}

Iglesia y convento adoptan una disposición en forma de «L», con el templo ocupando el lado más largo y el convento en ángulo a sus pies, organizándose sus dependencias en torno a un espacioso claustro de planta cuadrangular. De los muros de su piso bajo cuelgan ocho cuadros, dos por crujía, cada uno de los cuales mide $88 \times 99$ centímetros $(68,5 \times 58,5$ sin marco); es decir, cuadros de mediano formato que se prestan a la devoción íntima de la clausura ${ }^{5}$. Se trata de pinturas al óleo sobre lienzo de buena calidad, ejecutadas en el último cuarto del siglo XVII por un pintor que domina el dibujo y maneja con gran habilidad el color, pues la principal característica de los cuadros es su vivacidad y riqueza cromática. Rojos, amarillos y azules se combinan sutilmente con el verde del paisaje boscoso del fondo, realizado con una pincelada suelta que recrea efectos atmosféricos.

El paisaje se organiza en dos y hasta tres planos que se escalonan en profundidad, recurso frecuente en la pintura flamenca e italiana y que cuenta en España con numerosos ejemplos —quizás el de Francisco Collantes sea uno de los más significativos- que sin duda nuestro pintor tuvo que conocer. Las masas de árboles se recortan a contraluz sobre el celaje, en ocasiones cubierto de nubes que se abren para dar paso a un rompimiento luminoso, en tanto que el último término lo ocupan unas montañas que elevan el horizonte y clarifican la escena, rica en matices

\footnotetext{
${ }^{1}$ Archivo Catedral de Tarazona. Caja 77. Erección del Monasterio de Miedes.

${ }^{2}$ Rubio Semper, Agustín, «Convento de la Concepción de Miedes», Seminario de Arte Aragonés, XXIX-XXX, 1979, págs. 27-46. Idem, Estudio documental de las artes en la comunidad de Calatayud durante el siglo XvII, Zaragoza, Institución «Fernando el Católico», 1980, págs. 94-104.

${ }^{3}$ Archivo Histórico Diocesano de Tarazona. Religiosas Concepcionistas de Miedes (1695-1890). Mi agradecimiento a don Vicente González, Archivero Diocesano de Tarazona, y a $\mathrm{M}^{\mathrm{a}}$ Pilar Martínez, por la amabilidad con que atendieron mis consultas.

${ }^{4}$ Ibídem. Religiosas Concepcionistas de Miedes (1951- ).

${ }^{5}$ Quiero expresar mi gratitud a Ricardo Fernández Gracia, profesor del Departamento de Historia del Arte de la Universidad de Navarra, quien llamó mi atención sobre la presencia de los lienzos en la clausura aragonesa y me orientó en sus posibles fuentes de inspiración; y a Alberto Aceldegui Apesteguía, también profesor de dicho departamento, por la obtención del material gráfico.
} 
y contraluces. De vez en cuando en un plano intermedio se aprecian construcciones y monumentos concebidos a base de pinceladas blancas y grises. La riqueza de la composición se aprecia en sus múltiples planos acusados por los efectos de la luz y por la acumulación de elementos que dan gran variedad a la escena, agudizada con la gradación tonal de colores ocres, verdes y azules en planos sucesivos. Todo ello confiere a los lienzos un acentuado carácter escenográfico que sirve de marco a la historia religiosa que se desarrolla en primer plano, tal y como entienden Vicente Carducho o Francisco Pacheco la función de estos «países» en sus tratados de pintura ${ }^{6}$.

De indudable mérito resulta también la orla o cartela decorativa de elegante diseño en cuyo interior se inscribe la escena, configurada por varios elementos. En primer lugar, una guirnalda dorada recorre casi todo el perímetro, organizando un espacio ovalado. Sobre la guirnalda, y en la mitad superior, se disponen sendos angelitos de cuerpos rollizos y mofletes sonrosados que sostienen una filacteria en la que se inscribe el mote. Junto a ellos forman parte del repertorio ornamental, esta vez en su mitad inferior, dos cariátides o hermes femeninos de alas desplegadas cuyo cuerpo se prolonga mediante unos roleos vegetales. Del cuello de estos seres fantásticos cuelgan cintas azules o rosas que sostienen bellos pendientes de flores de gran variedad, entre las que se aprecian claveles, rosas, margaritas, narcisos y tulipanes; llama la atención su delicado tratamiento y el empleo de un color brillante a base de rojos, rosas y blancos, de vez en cuando salpicados por toques de azul y del verde de las hojas, lo que le permite conseguir un gran efecto decorativo. Los pendientes de flores flanquean una cartela central que contiene la inscripción del epigrama.

Ninguna de las cartelas es exactamente igual a las demás, de manera que los ángeles, de extraordinaria vivacidad y gracia, adoptan poses y miradas diversas, y en ocasiones su cabeza aparece tocada con una corona de flores. Lo mismo acontece con las esfinges, que se disponen tanto de perfil como de tres cuartos. También los ramilletes de flores varían, aunque se mantiene el virtuosisimo en la composición de todos ellos.

Tradicionalmente se ha venido atribuyendo a los lienzos un origen italiano, a lo que ha podido inducir el elegante diseño de la orla, relacionado con un manierismo retardatario que sigue de cerca la corriente italiana ${ }^{7}$. Es cierto que determinados elementos decorativos recuerdan a los empleados por algunos maestros boloñeses como Angelo Michele Colonna o Agostino Mitelli; mas para este momento eran ya conocidos en España a través de estampas y grabados y su uso resultaba frecuente. De esta manera, la riqueza y variedad decorativa de las cartelas que incluye Francisco Gómez de la Reguera en su obra Empresas de los Reyes de Castilla y León, se encuentra cercana a la de los lienzos aragoneses, y así, la Empresa VI, dedicada a Alfonso X el Sabio, muestra numerosas coincidencias en la disposición de las figuras femeninas aladas y de los racimos de flores ${ }^{8}$ (Fig. 1). Otros motivos similares pueden detectarse en las Empresas Sacras de Núñez de Cepeda, caso de la Empresa II, «Nescia necis» (Ignorante de la muerte), en la que aparecen de nuevo los hermes femeninos ${ }^{9}$, o en los Emble-

\footnotetext{
${ }^{6}$ La configuración del paisaje en los lienzos aragoneses se encuentra próxima a las disposiciones que sobre este género recoge Pacheco en su Arte de la Pintura, a cuyo juicio el paisaje no debe sacarse del natural, sino que tiene unas reglas propias de representación. Válidas son igualmente las recomendaciones del pintor sevillano sobre la aplicación de los colores y el esquema compositivo del primer plano. Pacheco, Francisco, El arte de la Pintura. Introducción, edición y notas de Bonaventura Bassegoda i Hugas, Madrid, Cátedra, 1990, págs. 513-514. Quesada Valera, José María, «La pintura de género en los tratados españoles del Siglo de Oro», Boletín del Museo e Instituto Camón Aznar, XLVII, 1992, págs. 73-74.

${ }^{7}$ Existe en la comunidad religiosa la creencia de que los lienzos proceden de Nápoles, desde donde habrían sido enviados, junto a un lienzo de la Inmaculada que se encuentra en el coro alto, por el jesuita Francisco Franco, primo de una de las religiosas del convento. Sin embargo, no nos ha sido posible confirmar documentalmente esta hipótesis.

${ }^{8}$ García Vega, Blanca, «Las empresas de los reyes de Castilla y de León de Francisco de la Reguera», Actas del I Simposio Internacional de Emblemática, Teruel, Instituto de Estudios Turolenses, 1994, págs. 93-169.

${ }^{9}$ Idea de el Buen Pastor copiada por los Santos Doctores representada en Empresas Sacras. Por el Padre Francisco Núñez de Cepeda de la Compañía de Jesús. El Leon, a costa de Anisson y Posuel, 1682, pág. 30.
} 
mas regio-políticos de Juan de Solórzano (véase por ejemplo los emblemas I y XXVI) ${ }^{10}$. Y tampoco debe dejarse de lado la relación que pueda establecerse con los modelos de Pedro de Villafranca y Malagón, uno de los más destacados grabadores de las décadas centrales del siglo XVII a quien Felipe IV nombró grabador de cámara en 1654, sustituyendo a Pedro Perret ${ }^{11}$.

En consecuencia, el diseño de las cartelas no resulta motivo suficiente para concretar la procedencia italiana de los lienzos. Por contra, su estilo parece remitir más bien a un pintor de la estimable aunque todavía poco conocida escuela aragonesa de la segunda mitad del siglo XVII, al que no resulta ajeno el conocimiento de la pintura de la Corte, donde pudo realizar su formación ${ }^{12}$. El círculo de pintores de la ciudad de Zaragoza, que reúne nombres como los de Bartolomé Vicente, Francisco de Vera Cabeza de Vaca, Jerónimo Secano, Pedro Aybar, Bernardo Polo, Francisco del Plano, o los Asensio, Pertus, y Pablo Rabiella, ya distinguidos por Palomino en su Parnaso Español Pintoresco y Laureado ${ }^{13}$, y recogidos más tarde por Ceán Bermúdez ${ }^{14}$, podría encontrarse detrás de las pinturas del convento de Miedes, a la espera de que la documentación nos permita concretar su autoría ${ }^{15}$.

\section{Un programa iconográfico inspirado en la Regia Via Crucis}

Mas el interés de los lienzos no reside tan sólo en su calidad pictórica; el conjunto compone además un programa iconográfico unitario y desarrolla una interesante catequesis muy propia de la espiritualidad barroca dirigida a las monjas de la comunidad religiosa. Y el punto de partida de todo ello se encuentra en una de las obras doctrinales más importantes del siglo XVII: la Regia Via Crucis, de Benedictus Van Haeften.

Benedictus Van Haeften fue natural de Utrech, capital de la provincia de Flandes, donde nació en 1588. Ya desde su niñez tuvo gran habilidad en componer versos. Tomó el hábito en el monasterio de Affliguen (Brabante), una de las primera abadías benedictinas en el Señorío

\footnotetext{
${ }^{10}$ González de Zárate, Jesús María, Emblemas Regio-Políticos de Juan de Solórzano, Madrid, Ediciones Tuero, 1987, págs. 44 y 79.

11 Véanse por ejemplo las ilustraciones de Pedro de Villafranca para obras como Vida de la Venerable Madre Feliciana de San Joseph, carmelita descalza y priora del convento de San Joseph de Zaragoza (1654); La Venerable Madre Teresa de Jesús, carmelita descalza del convento de Valladolid (1656); La Venerable Madre Catalina de Christo, carmelita descalza (1656); y Vida de la Sierva de Dios, Francisca del Santísimo Sacramento, carmelita Descalza, del Convento de San Joseph de Pamplona (1659).

${ }_{12}$ Quiero manifestar mi más sincero agradecimiento a don Alfonso Emilio Pérez Sánchez, doña Isabel Mateo, y doña Elena de Santiago, Jefe del Servicio de Dibujos y Grabados de la Biblioteca Nacional de Madrid, por la amabilidad con que atendieron mis consultas y las orientaciones proporcionadas al respecto.

${ }^{13}$ Palomino dedica la biografía n ${ }^{\circ} 203$ al pintor Bartolomé Vicente, de quien señala que estudió el arte de la pintura en la escuela de Carreño, y tras regresar a Zaragoza realizó excelentes países en los que destaca su hermoso colorido. La biografía nº 204 está protagonizada por Francisco de Vera Cabeza de Vaca, natural de Calatayud; y la $n^{\circ} 205$ por el grupo de pintores zaragozanos compuesto por Asensio (significado por su retratos), Bernardo Polo (por sus flores), Pertus (por sus países), Rabiella (por sus batallas) y Francisco del Plano (por su arquitectura y ornatos); de este último asegura que «no le hacían ventaja los célebres boloñeses Colona y Mitelli». La biografía $n^{\circ} 219$ corresponde al pintor y escultor Jerónimo Secano, también formado en la Corte. Palomino de Castro y Velasco, Antonio, El museo pictórico y Escala óptica, Tomo III, Madrid, Aguilar, 1988, págs. 489-91 y 549-50.

${ }^{14}$ En su Diccionario, Ceán alude al pintor zaragozano Asensio, distinguido por sus retratos; a Pedro Aybar, autor de excelentes lienzos en Calatayud; a Pertus; a Francisco del Plano, especializado en arquitectura fingida y adornos, aunque también pintó figuras e historias; a Bernardo Polo, de quien afirma que «se distinguió en pintar flores y frutas por el natural»; a Pablo Rabiella, cuyo estilo compara al de fray Juan Rizi en Castilla y Valdés Leal en Andalucía; a Jerónimo Secano; a Francisco de Vera Cabeza de Vaca, de quien ensalza sus retratos; y a Bartolomé Vicente, quien merced a su formación madrileña adquirió el gusto por el rico colorido veneciano. Ceán Bermúdez, Juan Agustín, Diccionario histórico de los más ilustres profesores de las Bellas Artes en España, Madrid, Reales Academias de Bellas Artes de San Fernando, 1965. Tomo I, págs. 79 y 88; Tomo IV, págs. 94, 103, 105, 141 y 361-62; y Tomo V, págs. 181-82 y 213-14.

${ }^{15}$ Diversas noticias sobre estos pintores son recogidas en la obra de Morales y Marín, José Luis, La pintura aragonesa en el siglo XVII, Zaragoza, Guara Editorial, 1980.
}

$A E A$, LXXVI, 2003, 302, pp. 133 a 152 
de Malinas, tras lo que se entregó al estudio de las letras, mereciendo entre los monjes el calificativo de «Viva Biblioteca». A la edad de 30 años alcanzó el cargo de Prior Mayor que desempeñó hasta el momento de su muerte en 1648. Fue al mismo tiempo un gran místico y un excelente investigador de las costumbres monásticas, terreno en el que sobresalen sus escritos Propugnacubium reformationis monasticae Ordinis S. Benedicti, Paradisus sive viridarium cathechisticum y Disquisitiones monasticae. Pero Van Haeften destacó igualmente en el terreno de la emblemática con dos obras de amplia difusión como son la Schola Cordis (Amberes, 1623) y la Regia Via Crucis ${ }^{16}$.

La primera edición de la Regia Via Crucis vio la luz en 1635 en Amberes, en la imprenta de Baltasar Moreto. Según indicaba el benedictino en su prólogo, el argumento de la obra parte de las palabras de Cristo recogidas por San Lucas 9, 22: «Si alguno quiere venir en pos de mí niéguese a sí mismo, lleve su cruz cada día, y sígame». La ascesis barroca en el marco religioso de la Contrarreforma no podía permanecer impasible ante las sugerentes implicaciones que entrañaba tal exigencia, al sintonizar con la principal de sus orientaciones teológicas: la que inducía, según el principio de la lectio divina, a la imitación del modelo primordial. Por ello, la recuperación de clásicos medievales como la Imitatio Christi de Tomás de Kempis, o la creación ex novo de obras como la Schola cordis o la Regia Via Crucis de Van Haeften, obedecen a ese afán de excitar el cultivo personal del espíritu que ayuda a cada cristiano, según la atmósfera didáctico-doctrinal dominante, a soportar con eficacia la «cruz» de sus propias circunstancias y avatares ${ }^{17}$. Todavía a comienzos del siglo xviII el ejemplo de la cruz permanecía vivo, como puede comprobarse en la obra Mater amoris et doloris del padre Antonio Ginther (1711), cuya consideratio XL, con el mote «No hay sombra más segura que ésta», alude a la sombra protectora de la cruz.

En consecuencia, el tratado de Van Haeften se convierte en una guía de meditación, un tratado de teología mística destinado a las almas contemplativas en el que se exponen las tres vías o caminos de la vida espiritual que sirven para orientar al hombre cristiano en el difícil camino de la vida terrenal, y que regularmente señalan los místicos para alcanzar la perfección espiritual y con ello la vida eterna. Van Haeften puso de manifiesto cómo el tema de la cruz, y con ella el de la Pasión de Cristo, se encontraba en la inquietud de las personas con preocupaciones de perfección religiosa, anticipándose así a un místico excepcional, el sacerdote italiano San Pablo de la Cruz (1694-1775), fundador de los pasionistas. La Pasión, que pone de relieve el aspecto humano de Cristo Dios, era muy adecuada para sugerir al alma cristiana su conversión hasta llegar a ser «alter Christus» ${ }^{18}$.

La guía está compuesta por tres libros con un total de 48 capítulos, y se desarrolla en forma de diálogo entre Cristo, que se muestra como divino conductor y nos indica el camino de la vida eterna, y Staurofila, doncella cuyo nombre significa «Amante de la Cruz». A juicio de Van Haeften, el diálogo resulta el método más adecuado para la transmisión de la doctrina, a lo que contribuye también la inclusión de breves composiciones poéticas y de 37 estampas grabadas que cumplen la función pedagógica de visualizar la meditación escrita, como es costumbre general de la época, en el marco de las directrices impuestas por la Contrarreforma ${ }^{19}$.

\footnotetext{
16 A la importancia e influencia de ambas alude Santiago Sebastián en su obra Contrarreforma y Barroco, en sendos capítulos dedicados al «Simbolismo espiritual del corazón» y al «Seguimiento de la Cruz» respectivamente. Sebastián, Santiago, Contrarreforma y barroco, Madrid, Alianza Editorial, 1981, págs. 322-26 y 329.

${ }_{17}$ Sánchez López, Juan Antonio, «Contenidos emblemáticos de la iconografía del Niño de Pasión en la cultura del Barroco», Actas del I Simposio Internacional de Emblemática, Teruel, Instituto de Estudios Turolenses, 1994, pág. 705.

${ }^{18}$ Sebastián, Santiago, «Los emblemas del Camino Real de la Cruz de Van Haeften», Boletín del Museo e Instituto Camón Aznar, XLIV, 1991, pág. 26.

${ }^{19}$ Así queda de manifiesto en el prólogo del autor: «Este mismo método, consta, que amaron, y siguieron Platón, y Tulio, y de los Santos Padres, Agustino, Chrisostomo, y nuestro Gregorio el Grande; y aun el mismo Espiritu Santo, aquel
} 
Obra de esta naturaleza no podía tardar mucho en difundirse por el ámbito europeo y llegar a España, donde el tema de la repartición de cruces y sufrimientos adquiría en la segunda mitad del siglo XVII pleno significado. Ya en la centuria anterior Santa Teresa de Jesús escribía unos versos exaltando la cruz ${ }^{20}$, e iconografías como la del santo con la cruz a cuestas, Cristo cargando con la cruz sobre un campo de cruces, o los temas de la infancia de Jesús con contenido de Pasión ${ }^{21}$ —afirma en este sentido Emil Mâle que la idea de asociar la infancia de Cristo con su Pasión se intensificó a partir del siglo $\mathrm{XVI}^{22}$-, son frecuentes tanto en las creaciones literarias místicas y espirituales como en las representaciones plásticas, todas ellas de honda tradición popular y devota (Fig. 2). De tal manera que a los pocos años de su publicación el tratado era conocido en nuestro país e incluso se planteó su traducción del latín al castellano, según se desprende de las palabras de don Juan de Palafox y Mendoza en el prólogo de su Philotea, obra que el prelado escribió al inicio de su episcopado en Osma ${ }^{23}$. Sin embargo, Palafox se decantó finalmente por componer una obra original a partir del argumento de la Regia Via Crucis, a la que intituló Peregrinación de Philotea al Santo Templo, y Monte de la Cruz, que llevó a cabo en un breve espacio de tiempo, entre los meses de abril y julio de 1657 (Fig. 3). La traducción castellana del tratado de Van Haeften tuvo que esperar hasta 1721, año en el que el también benedictino fray Martín de Herce, Predicador General de la Congregación de Valladolid, publicaba en Valladolid y Madrid el Camino Real de la Cruz (Fig. 4). Nuevas reediciones fueron llevadas a cabo en Madrid (1755 y 1785), Valladolid (1821) y Barcelona en la tardía fecha de 1890, lo que constituye buena muestra de la aceptación que tuvo la obra entre el público español. De la edición original latina hubo dos nuevas ediciones en 1712 y 1728, ambas en la oficina de Enrique y Cornelio Verdusán en Amberes, y también se tradujo al holandés y al francés.

Un libro de las características de la Regia Via Crucis no podía pasar inadvertido a los artistas. Ya Santiago Sebastián descubrió en el Museo del Azulejo de Lisboa un conjunto de 30 azulejos portugueses inspirados en los grabados que ilustraban el tratado, de los que afirmaba que «si bien no se conoce su procedencia su origen debe de estar en el claustro de algún convento, donde fueron colocados no como mera decoración sino para recordar a los frailes o a las monjas lo importante que era la representación visual y que incluso no era precisa la lectura una vez que el texto de Van Haeften había sido conocido» ${ }^{24}$. Una vez más nos parece suma-

ephitalamio de amor de los Cantares, le dibuxó, y pintó con flores de coloquios, porque logicamente suelen ser más graciosas las interlocuciones, que los discursos dilatados. Por más que se sazone, no rara vez queda desabrido el trato de una continuada uniforme oración, y las más causa tedio con la encadenada igualdad, y semejanza de sentencias, que unas a otras se suceden, y por esta razón hemos ingerido en esta obra versos, y estampas, para que de algún modo templen el horror que la Cruz, y tribulación suelen traer consigo, y deleiten al mismo tiempo, no poco al lector».

${ }^{20}$ Dice Santa Teresa: «En la cruz está la vida / y el consuelo, / y ella sola es el camino / para el cielo».

${ }^{21}$ Según Santo Tomás, Jesús, desde el primer momento de su concepción, tuvo como pensamiento la cruz. En la misma línea se manifiesta el mercedario fray Juan Interián de Ayala al criticar a los artistas que representaban al niño Jesús entretenido en juegos, pues «Cristo nuestro Señor desde el primer instante de su conceción, aceptó espontáneamente la muerte y acerbísima Pasión, que le impoeso su Eterno Padre, viviendo siempre aparejado para ella y pensando en ella muchas veces: sabiendo muy bien que con su muerte vencería a la misma muerte y al demonio... Por lo que es mucho mejor pintarle como que está orando a su Eterno Padre, abrazando la cruz, o arrodillado sobre ella». Interián de Ayala, fray Juan, El pintor cristiano y erudito, o Tratado de los errores que suelen cometerse frecuentemente en pintar y esculpir las imágenes sagradas, Barcelona, Imprenta de la Viuda e Hijos de J. Subirana, 1883, pág. 248.

${ }^{22}$ La visión del Niño Jesús Nazareno fue una de las iconografías más fructíferas ya desde el siglo xvi, como lo demuestran las distintas versiones del tema realizadas por El Greco o las obras de Luis de Vargas y Francisco de Ocampo, y continuará vigente con toda su carga devocional incluso hasta el siglo xIx. Sánchez López, Juan Antonio, op. cit., págs. 685-718.

${ }^{23}$ Obras del Ilustríssimo, Excelentíssimo, y Venerable Siervo de Dios don Juan de Palafox y Mendoza, Tomo VI, en Madrid: En la Imprenta de Don Gabriel Ramírez, Año de 1762, págs. 333-34. Azanza López, José Javier, «Motivos emblemáticos y cultura simbólica en la obra de don Juan de Palafox y Mendoza», Boletín del Museo e Instituto Camón Aznar, ${ }^{\circ}$ LXXXVI-LXXXVII, 2001-2002, págs. 56-62.

${ }^{24}$ Sebastián, Santiago, «Los emblemas del Camino Real de la Cruz de Van Haeften», Boletín del Museo e Instituto Camón Aznar, XLIV, 1991, pág. 7.

AEA, LXXVI, 2003, 302, pp. 133 a 152 

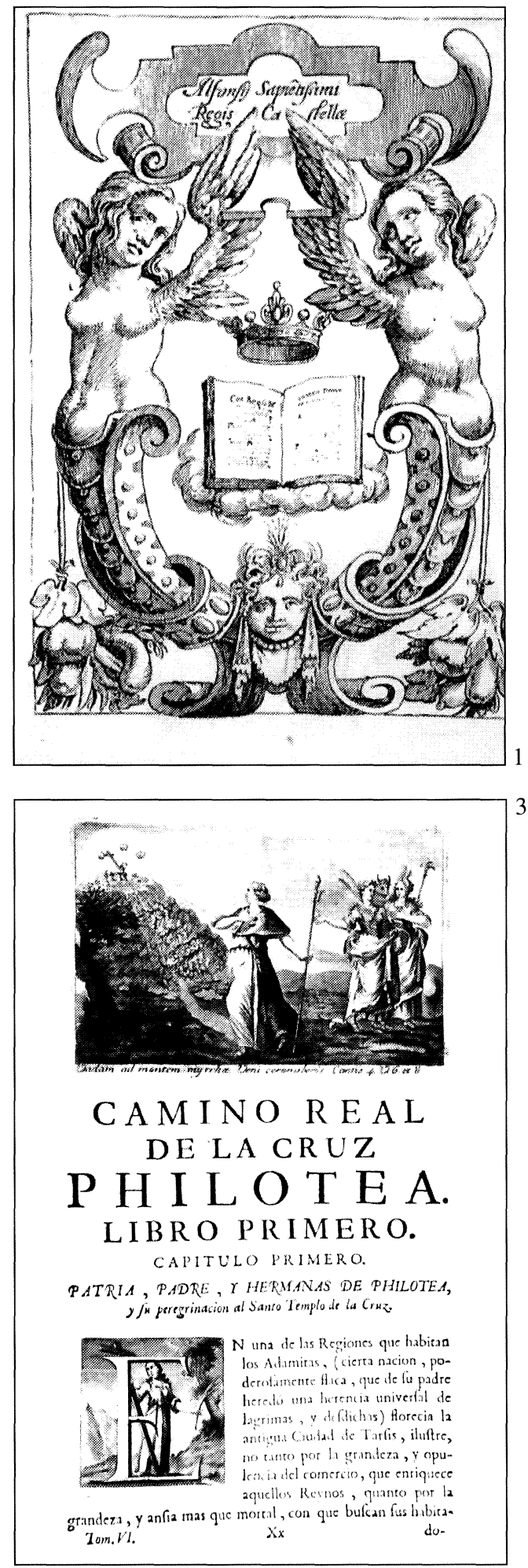

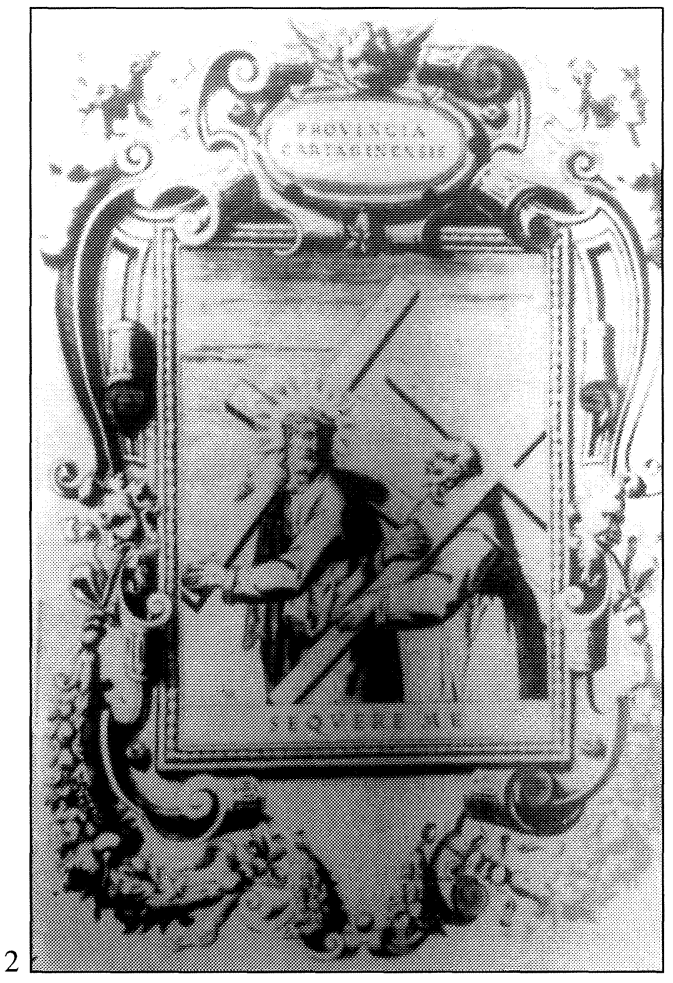

4

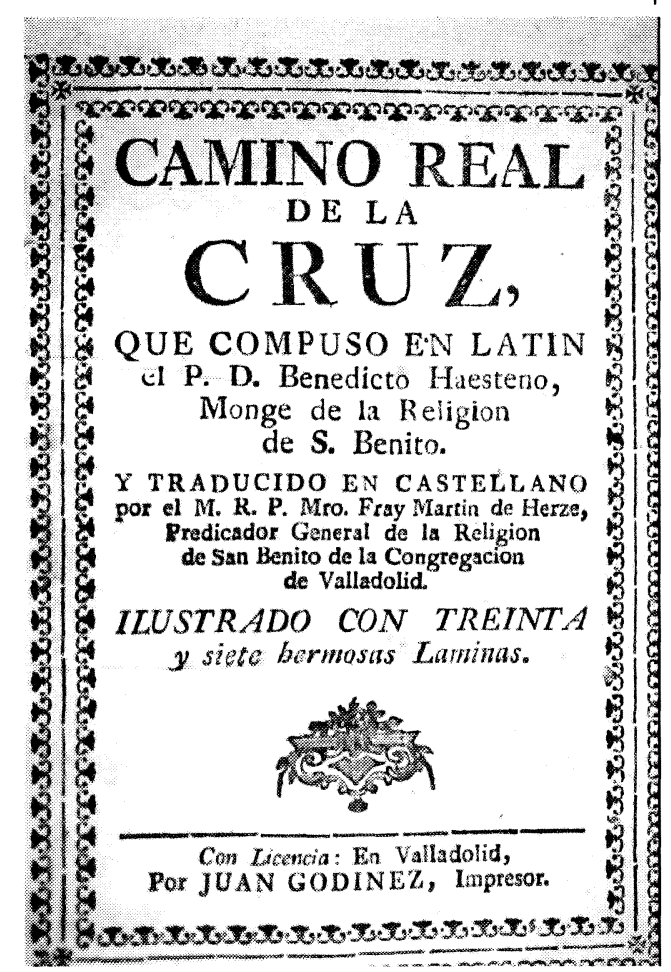

Fig. 1. Francisco Gómez de la Reguera. Empresas de los Reyes de Castilla y León. Empresa VI.

Fig. 2. Giovanni Crespi. Alegoría de la Provincia Franciscana de Cartagena (1587).

Fig. 3. Juan de Palafox. Peregrinación de Philotea al Santo Templo, y Monte de la Cruz.

Fig. 4. Fray Martín de Herce. Camino Real de la Cruz. 
mente acertada la hipótesis del maestro a tenor de la ubicación que ocupan en el convento de la Concepción de Miedes los lienzos elaborados siguiendo al pie de la letra el tratado del monje benedictino. Los ocho lienzos del convento aragonés están inspirados en otras tantas estampas que ilustran el tratado: cuatro pertenecen al Libro I, dos al Libro II y las dos últimas al Libro III. Por razones cronológicas, el pintor debió de utilizar la edición príncipe de la Regia Via Crucis, que sigue al pie de la letra, si bien introduce pequeñas modificaciones en algunos cuadros encaminadas a enriquecer el tema o motivo representado. Cada grabado adopta la estructura de «emblema triplex», pues se compone de mote o lema, cuerpo o pictura, y epigrama o subscriptio, que constituye el alma del emblema y explicita su significado. Precisamente en el epigrama es donde se encuentra la principal novedad con respecto a la fuente empleada por el pintor, pues el de la pintura no se corresponde con el del grabado, sino que ha sido sustituido por el título del capítulo correspondiente.

El primer lienzo (Fig. 5) tiene como mote las palabras del profeta Isaías: «Haec est via, ambulate in ea. Isai, 30, 21» (Éste es el camino, andad en él). Dice el epigrama: «Crux certa ad Caelum via: omnibus perambulanda» (La Cruz es el camino cierto para el cielo, que deben andar todos), título del capítulo II del Libro I de la Regia Via Crucis, que constituye su fuente grabada (Fig. 6). Se trata de la primera de las estampas que ilustran el texto. Para su mejor comprensión resulta necesario conocer el argumento de la obra, que tiene como escenario la ciudad de Tarsis en la que vivía Phileto, varón noble y poderoso, junto a las tres hijas que le habían quedado de su difunta esposa. La mayor se llamaba Staurofila, es decir, «Amante de la Cruz», nombre que recibió al nacer el mismo día en que celebra la Iglesia el misterio inefable de la Cruz. La segunda hermana se llamaba Hilaria y la tercera y menor de todas, Honoria; tampoco resultaban gratuitos sus nombres, pues Hilaria se dejaba guiar por los deleites, placeres y diversiones, en tanto que Honoria aspiraba a las honras, riquezas, y felicidades del mundo. Un día de primavera en que las tres habían salido a pasear por la huerta de su padre, tuvo Staurofila el deseo de visitar en un bosque cercano una capilla dedicada a la Santa Cruz. Animó a sus hermanas a acompañarla, pero ellas desistieron, por lo que se adentró ella sola en la espesura. Al ignorar el camino, pasó de largo el templo y acabó perdiéndose, aumentando su congoja al ver que se aproximaba la noche. Apostada al cobijo de un haya, Staurofila supo interpretar en su interior lo que le había ocurrido, y solicitó el auxilio divino no tanto para salir de la selva como para hallar la senda recta de la vida.

No desoyó el Señor las súplicas que le eran dirigidas, y para consolar a Staurofila, se le apareció Cristo «en la forma de un Joven hermosísimo, de quien se desprendía una inundación de rayos, y un piélago de luces». A partir de estos momentos se inicia el diálogo entre la muchacha y Jesús, quien le hace saber que ha bajado para enseñarle el camino que anhelaba su alma: es un nuevo camino que conduce a la vida eterna a los que entran en él, y es el camino de la cruz. Estas palabras sobresaltan a Staurofila, horrorizada ante el hecho de que el Señor no predicase más que la cruz. Tranquiliza el maestro a la joven, pero a la vez le recuerda que en este valle de lágrimas no hay gozo sino trabajo y aflicción. Al comprender la muchacha la llamada de Cristo, respondió que estaba dispuesta a recorrer el áspero y estrecho camino que le proponía, emprendiendo la senda de la cruz. El Señor le aseguró que no la desampararía, pues iría delante y estaría a su lado en toda angustia y tribulación.

La composición recoge de manera gráfica lo anteriormente señalado. Sobre un fondo paisajístico con sus valles, bosques y montañas, Cristo muestra a Staurofila un camino ondulante y áspero lleno de cruces, visión que parece sorprender a la muchacha por el gesto que hace con sus brazos. El camino asciende hasta una cruz rematada en corona y enmarcada en una florida glorieta. Se trata del camino de la cruz, que lleva a la vida eterna a los que entran por él. Es el camino que Cristo propone a todos los hombres por ser el camino de la verdad, de la 

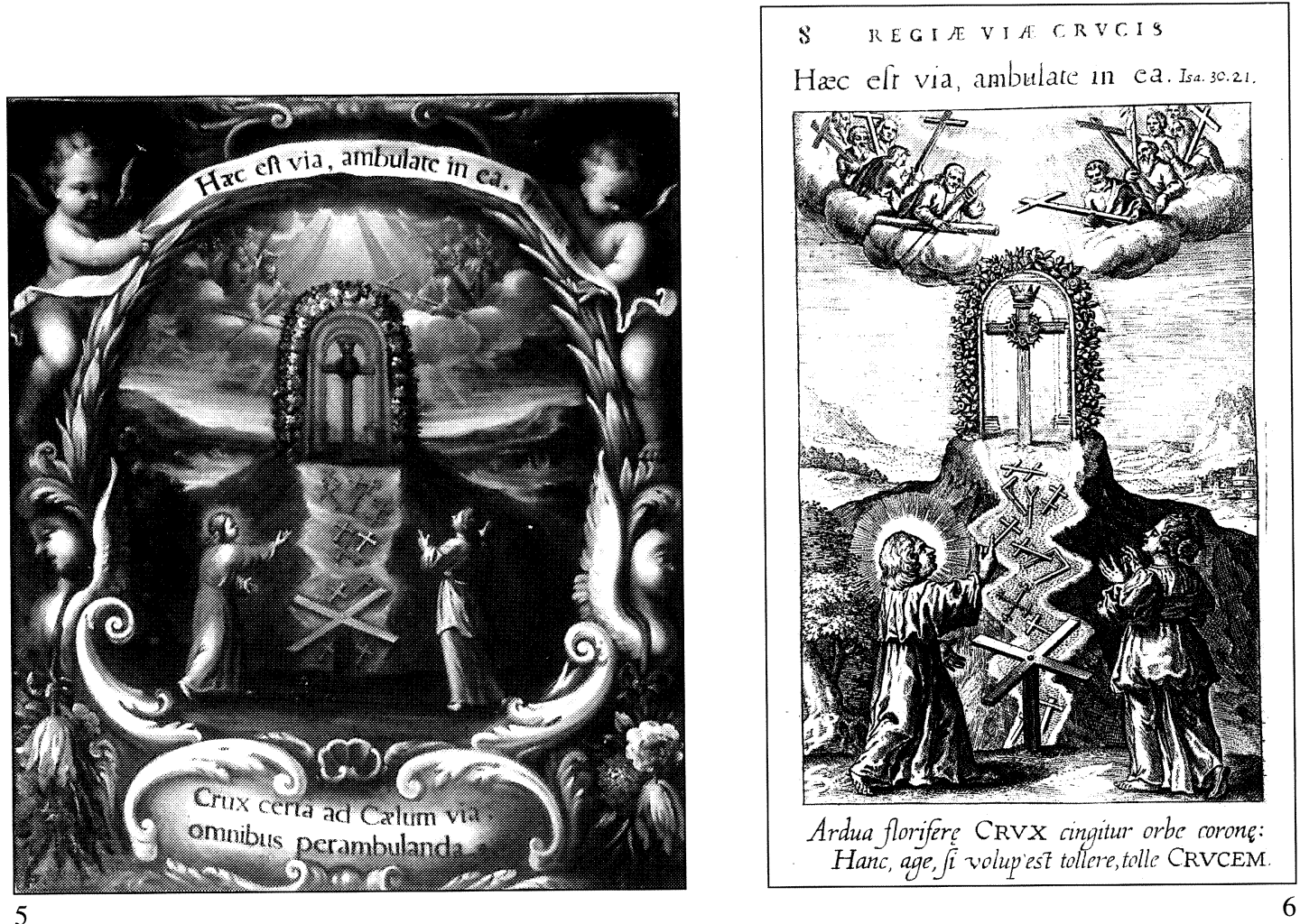

5
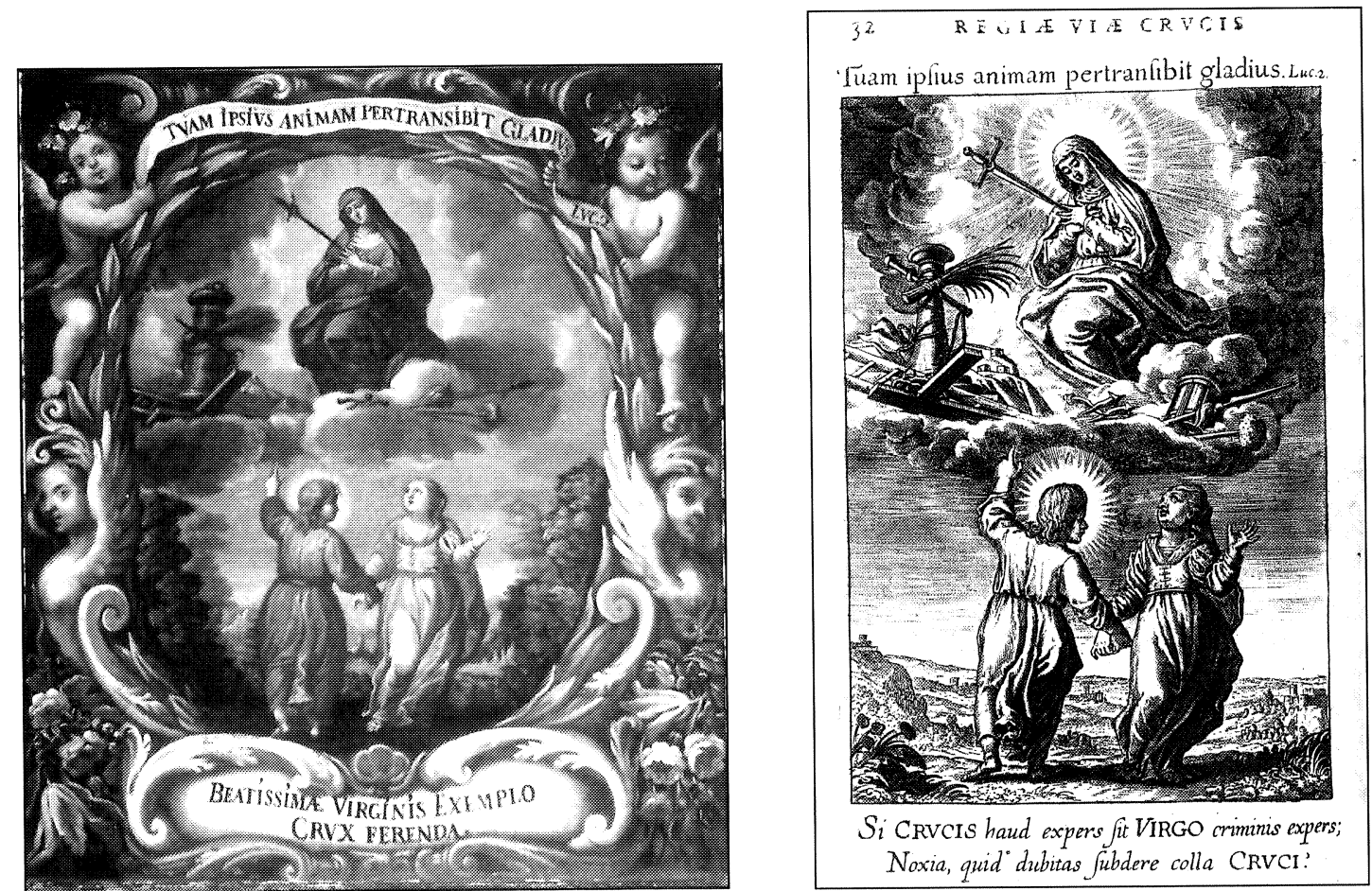

7

Fig. 5. Primer lienzo del Convento de Concepcionistas. (Foto. A. Aceldegui).

Fig. 6. Benedictus Van Haeften. Regia Via Crucis. Libro I, capítulo II.

Fig. 7. Segundo lienzo del Convento de Concepcionistas. (Foto. A. Aceldegui).

Fig. 8. Benedictus Van Haeften. Regia Via Crucis. Libro I, capítulo V.

$A E A$, LXXVI, 2003, 302, pp. 133 a 152 
vida, de la gloria y del reino. Así lo demuestra la parte superior del dibujo, en la que el cielo se abre para mostrar a los bienaventurados que disfrutan ya de la visión de Dios; todos ellos portan en sus manos la cruz que arrastraron en su vida terrena. Apenas existen diferencias entre grabado y pintura, si bien en esta última el paisaje aparece trabajado con mayor minuciosidad frente al sintetismo de aquél.

Avanzamos así hasta el lienzo segundo (Fig. 7), cuyo mote está tomado del Evangelio de San Lucas 2, 35: «Tuam ipsius animam pertransibit gladius. Luc. 2» (Una espada te traspasará el alma $)^{25}$. Por su parte, en el epigrama podemos leer: «Beatissimae Virginis Exemplo crux ferenda» (Que se debe llevar la cruz con el ejemplo de María Santísima). En esta ocasión se trata del título con el que se inicia el capítulo V del libro I de la obra de Van Haeften, en el cual está inspirada la pintura (Fig. 8).

En la escena anterior hemos podido comprobar cómo Staurofila se mostraba dispuesta a recorrer el camino de la cruz; no obstante, no deja de parecerle excesivo el precio que hay que pagar para alcanzar el reino de los cielos. Para sacarla de su error, el Señor recurre a una anécdota, y pide a la muchacha que le cuente lo ocurrido al comprar un vestido nuevo. Ella dice que regateó con el mercader, pues le parecía muy costoso; a lo que el mercader replicó: «Mira, una o dos calles distante de aquí habita mi Madre, quien compró no a más baxo precio el mismo paño; llégate a ella, y oye de su boca si es así como lo digo, y conocerás que no pido injustamente».

Con este ejemplo, Jesús quiere demostrar que el precio de la cruz para entrar al reino de los Cielos no es elevado, pues incluso su Madre lo pagó: «¿Acaso mi Madre Inmaculada (en quien no hubo la menor tintura de terrenos afectos, sino que instruida con celestiales pensamientos, siendo un Cielo animado) no compró con el mismo precio el Cielo? Y si alguna criatura libre de Cruz pudiera ser admitida a la eterna bienaventuranza, ¿no te parece a ti que entre todas ellas sería singularmente privilegiada mi Madre Santísima?». Manifiesta Staurofila su deseo de escuchar los dolores y cruces de la Virgen, y Cristo pasa a referirlos, con el propósito de acrecentar en ella la reverencia y culto hacia la Madre de Dios para que trate de seguir su ejemplo. Muchos de los sufrimientos padecidos por María tienen lugar en los años,anteriores a la Pasión: el alumbramiento en un frío y pequeño establo, el decreto de Herodes, la huida y estancia en Egipto durante siete años, o la desaparición en el templo. También causaron dolor en su alma la noticia de la encarcelación y muerte de Juan Bautista, o el fallecimiento de su amado esposo José ${ }^{26}$.

Ante estas palabras, Saturofila no puede menos que manifestar su sorpresa, pues no había reparado en el hecho de que con anterioridad a la Pasión del Señor la Virgen se hubiera visto

\footnotetext{
${ }^{25}$ Se trata de las palabras dirigidas por el sacerdote Simeón a la Virgen el día de la Presentación de Jesús en el templo, anunciándole los duros momentos de la Pasión: «Y después de dar gracias a Dios por haber visto al Salvador del mundo, dijo a su María, su Madre: Mira que este Niño está puesto en el mundo para la caída y levantamiento de muchos en Israel; y por una señal, a quien ha de contradecir el mundo. Y tu ánimo será atravesado con una espada, para que sean descubiertos los pensamientos de muchos». El episodio será objeto de la reflexión de fray Luis de Granada, quien en su Libro de la oración y meditación (1554), pone en boca de la Virgen esta frase dirigida al Padre, mientras sostiene en brazos a su hijo muerto: «Vos sabéis que desde el día en que aquel Santo Simeón me anunció este martirio, se echó acíbar en todos mis placeres y desde entonces traigo este día atravesado en mi corazón». Granada, fray Luis de, Libro de la oración y meditación, Madrid, Ediciones Palabra, 1979, págs. 302-303.

${ }^{26}$ Señala a este respecto Domingo Sánchez-Mesa que los temas iconográficos marianos de Pasión pueden agruparse en dos grandes apartados. En el primero se incluirían las premoniciones y presentimientos de la Pasión, junto con otros momentos recogidos por los evangelios como la Huida a Egipto o el Niño perdido y hallado en el Templo, a los que se les ha dado explicación dolorosa; y otros como la despedida de Jesús de su Madre, creados o profundizados por la devoción de las meditaciones místicas, y popularizados por las representaciones de los misterios medievales. El segundo grupo estaría formado por los pasos y escenas de la Pasión real de Cristo en los que la Virgen está presente según los evangelios o según las narraciones devotas y composiciones místicas y piadosas. Sánchez-Mesa Martín, Domingo, «Los temas de la Pasión en la iconografía de la Virgen», Cuadernos de Arte e Iconografía. Actas de los II Coloquios de Iconografía, Tomo 4, nº 7 , 1991, págs. 167-85.
}

AEA, LXXVI, 2003, 302, pp. 133 a 152 
anegada en tantas cruces. Asegura Cristo sin embargo que todas ellas fueron un simple preludio de los dolores que como río impetuoso le acometerían con furia en el momento de la Crucifixión, cuando al pie de la cruz una espada de dolor atravesó su corazón: «Entonces, según Jeremías ${ }^{27}$, se apoderaron de ella, como de muger que se halla en la presura de el parto, las angustias, y dolores. Y las congoxas que no tuvo en el parto, experimentó pariendome segunda vez herido en la materna compasión de sus entrañas». Por todo ello concluía Cristo su enseñanza: «Todas estas cosas, hija, se han traído, para que veas clarísimamente que ni mi madre estuvo libre de cruz; y que por esto ni tú ni otro alguno debe ser indultado de ella». La cruz es necesaria y no se la puede rehuir, quieran o no los hombres.

La escena representada en el lienzo muestra la anterior enseñanza. Cristo, de espaldas a nosotros, toma la mano de Staurofila y señala con la otra hacia los cielos, donde entre nubes aparece la Virgen de los Dolores con el corazón traspasado por una espada y las manos cruzadas sobre el pecho; como ya hemos significado, el origen de esta representación es la profecía del anciano Simeón que anuncia a María el día de la Presentación de Jesús en el templo, que una espada de dolor le atravesará el alma. Viste la Virgen túnica rosa y manto azul que cae sobre el rostro, ligeramente inclinado hacia la derecha, dejando casi en penumbra los ojos llorosos de los que brotan lágrimas que resbalan sobre sus mejillas y humanizan su serena expresión ${ }^{28}$. A su alrededor se encuentran los instrumentos de la Pasión: a un lado, la columna, el látigo, el azote, la cruz, la escalera, la túnica y los dados; y al otro los clavos, el farol, la lanza que atravesó el costado a Cristo del que manó sangre y agua, y la caña con la esponja empapada en vinagre. María se convierte así en la fortaleza que permite al cristiano llevar la cruz, y todos nosotros debemos tratar de seguir su ejemplo. Nuevamente el grado de identidad entre pintura y grabado resulta elevado.

El lienzo tercero (Fig. 9) lleva por lema la frase del Libro de los Proverbios: «Pondus et statera judicia Dni, sunt. Prov. 16, 11» (Peso y balanza son los juicios de Dios). Y el epigrama refiere lo siguiente: «Cuiusque Viribus crucem a Deo Contemperari» (Que Dios mida la cruz por las fuerzas de cada uno). El punto de partida de la composición se encuentra en el grabado que ilustra el capítulo VII del Libro I de la Regia Via Crucis (Fig. 10).

El ejemplo de María anima a Staurofila a aceptar la carga de la cruz, si bien todavía se ve asaltada por ciertas dudas que no quiere dejar de transmitir al Señor. Así, pregunta cómo serán todos capaces de llevar la cruz, siendo tan desiguales las fuerzas humanas, pues lo que a uno le parecerá carga ligera para otro será pesadísima. Para calmar su inquietud, Cristo acude a la Sabiduría divina; el Señor conoce exactamente el peso que puede soportar cada persona sobre sus hombros y a nadie otorgará una cruz superior a sus fuerzas: «Por eso examina con igual medida las aflicciones, y las penas; para que a ninguno se le imponga más corta o larga Cruz de lo razonable. Él numera quantas Cruces, y con qué orden se han de señalar a éste, y a aquél: fuera de esto pesa, como en balança, de una parte el peso de cada Cruz, y de otra las fuerzas de cada uno, y de tal suerte lo templa todo, que en cosa alguna se haga insoportable al paciente». En definitiva, Dios en su sabiduría y al margen de cualquier ira repentina, envía a cada uno las enfermedades y aflicciones que le han de aprovechar para la salvación de su alma.

La Sabiduría y Justicia divinas quedan perfectamente plasmadas en el lienzo. En la parte superior se encuentra Dios Padre en un trono de nubes, portando el cetro en su mano derecha que hace descansar sobre la esfera del mundo; a su lado, un ángel pesa una cruz con la balanza. Desde el cielo desciende otro ángel que entrega a una mujer la cruz que le corresponde.

\footnotetext{
${ }^{27}$ Se refiere a las palabras del profeta Jeremías 49, 24: «Es presa de angustia y de dolores como mujer en parto».

${ }^{28}$ Sobre la riqueza iconográfica de los Dolores de María en el arte y la literatura españoles, puede consultarse el artículo de R. Gutiérrez de Ceballos, Alfonso, «La literatura ascética y la retórica cristiana reflejados en el arte de la Edad Moderna: el tema de la Soledad de la Virgen en la plástica española», Lecturas de Historia del Arte, nº II, 1990, págs. 80-90.
} 
Cristo muestra la escena a Staurofila, quien también lleva una cruz, al igual que otro personaje que camina por detrás de ambos. A juicio de Santiago Sebastián, la escena recuerda un pasaje recogido por Baltasar Gracián en su Arte de ingenio y agudeza ${ }^{29}$. Estampa y lienzo son muy parecidos, si bien en el caso de las ediciones castellanas el grabado ha sido invertido.

Las palabras de los salmos constituyen el mote del cuarto lienzo (Fig. 11) del programa: «Multa flagella peccatorum. Psal. 31, 10» (Muchos son los azotes del pecador). Dice el epigrama: «Peccatoribus maiorem a Doemoni imponi crucem» (Una cruz mayor es impuesta a los pecadores por los demonios). En este caso, la relación del lienzo se establece con el capítulo XI del Libro I de la obra del benedictino Van Haeften, el cual carece de título (Fig. 12).

En este episodio le viene a Staurofila el recuerdo de sus hermanas que han abandonado el camino de la cruz, a la que rechazan y desprecian, alejándose para vivir sin penas en delicias y honores. Pregunta a Cristo si quedarán libres de la cruz todas aquellas personas que optan por esta vía. «De ninguna suerte estarán aquí libres de Cruz — responde el Señor-, porque el que rehúsa seguirme por medio de la cruz, siempre la cruz le seguirá a él. No hay mortal alguno que se libre del dolor. A la manera que todos mueren, también padecen todos: y así como cualquier muerto tiene su sepulcro, también viviendo tiene su cruz».

Insiste Staurofila en que los hombres se sienten atraídos por muchos placeres, y siguen sus propios gustos, de manera que son pocos los que ponderan sus tribulaciones y cruces. A su juicio, reyes, príncipes, emperadores y todos aquellos que ejercen el dominio, participan muy poco de la cruz. Pero le replica Jesús que son muchas y muy pesadas las cruces que cada día aguardan a los poderosos que se abandonan a los falsos dioses del mundo: «El peso de los pecadores es como el talento de plomo, que qual pesada carga los abruma. Después sirven estos de día, y de noche a agenos dioses que no los dexan descansar. Todo lo que se peca, todo lo que de malo que de día, y de noche se obra es imperio de los demonios, que nunca permiten descanso, sino que siempre impelen a añadir delitos a delitos, y aumentar el cúmulo de los pecados». Frente a ello, insiste el Señor en que su yugo es suave y su carga ligera (Mateo 11, 30), y quienes los lleven hallarán el descanso para sus almas.

«Veo clarísimamente - dice Staurofila- que no tienen una cruz sola los malos; pero con todo eso parece que pasan la vida con mucha quietud, y tranquilidad, del todo seguros de los peligros que los amenazan». Cristo le responde que se trata de una mera apariencia: «Atorméntalos la conciencia de los delitos, ni aquel gusano que continuamente está royendo les concede algún descanso. ¿Juzgas ahora, Staurofila, felices a estos en quienes se derraman las riquezas, el poder, y los deleites? Verdaderamente no lo son, entretanto que el verdugo de la conciencia cada día los hiere y punza con menudas heridas, y con lento paso los lleva a la muerte eterna».

El lienzo está dedicado, por tanto, a los que huyen de la cruz para entregarse a los placeres del mundo, quienes acaban por soportar una carga más pesada. Cristo acompaña a Staurofila, que se muestra gozosa de haber aceptado la cruz, y por eso recibe las bendiciones del cielo, que le llegan en forma de rayos. La joven porta la cruz — de considerable tamaño- sin apenas esfuerzo, como si resultara muy ligera de llevar. A su lado, el Maestro le señala la escena que se desarrolla en el paisaje de fondo: dos muchachas arrastran pesadas cruces sin encontrar alivio ni descanso, hasta el punto que una de ellas dobla las rodillas y cae al suelo; la segunda, que también se inclina ante el peso de la cruz, va ataviada con ricas joyas en forma de broches, un collar y pendientes de perlas, por lo que debemos deducir que se trata de Hilaria y Honoria, las hermanas de Staurofila. Pero, además de su cruz, ambas tienen que soportar una carga más pesada que un demonio alado les muestra: una cruz más grande, de la que no podrán librarse a lo largo de su peregrinación por este mundo. También en este caso la relación

${ }^{29}$ Sebastián, S., «Los emblemas del Camino Real de la Cruz...», págs. 10-11.

$A E A$, LXXVI, 2003, 302, pp. 133 a 152 

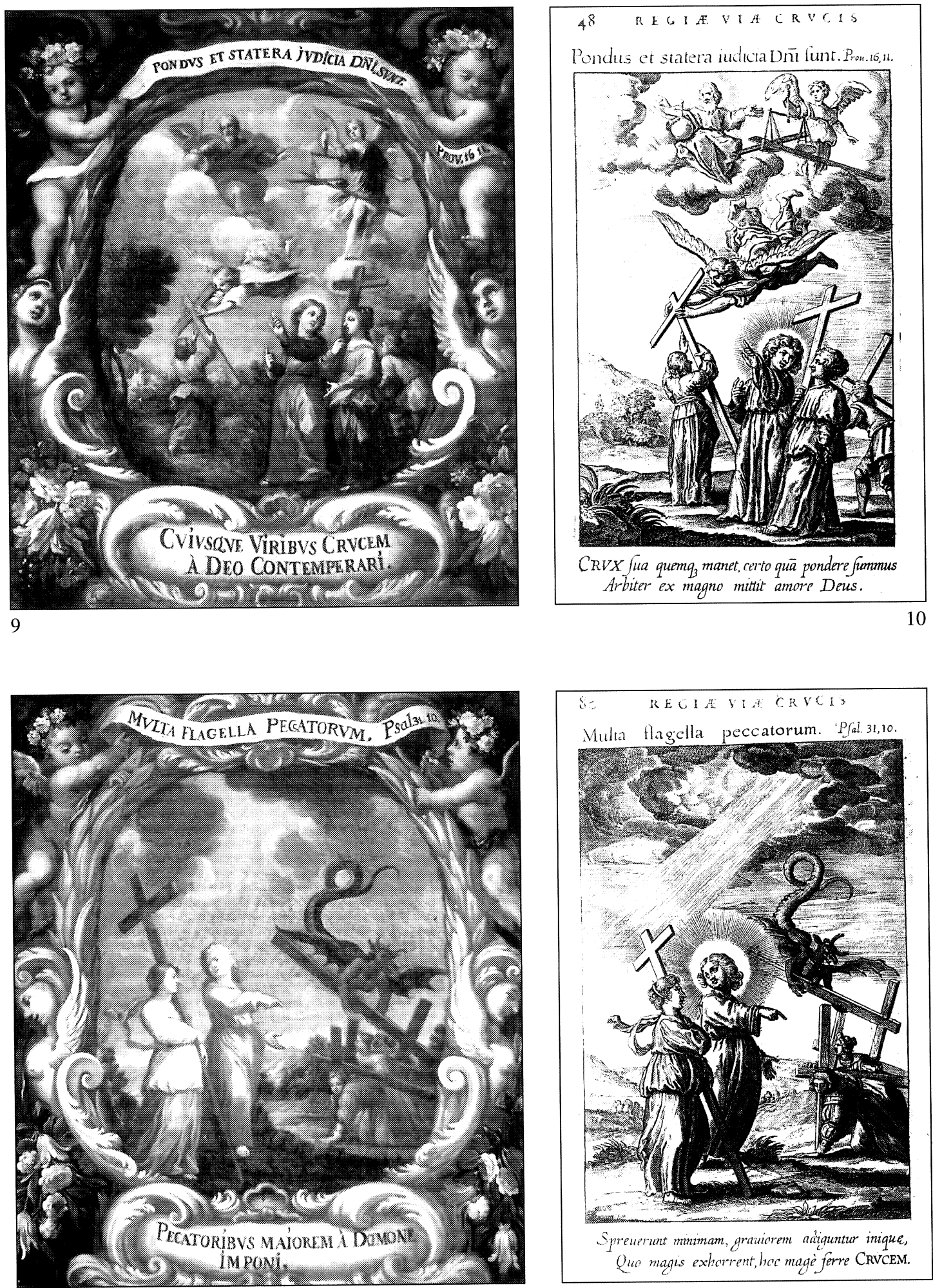

11

Fig. 9. Tercer lienzo del convento de Concepcionistas. (Foto. A. Aceldegui)

Fig. 10. Benedictus Van Haeften. Regia Via Crucis. Libro I, capítulo VII.

Fig. 11. Cuarto lienzo del Convento de Concepcionistas. (Foto. A. Aceldegui)

Fig. 12. Benedictus Van Haeften. Regia Via Crucis. Libro I, capítulo XI.

$A E A$, LXXVI, 2003, 302, pp. 133 a 152 
entre grabado y pintura es evidente, aunque al igual que en el anterior, los motivos aparecen invertidos en las ediciones castellanas.

Alcanzamos el quinto lienzo (Fig. 13), cuyo mote está tomado del evangelista Mateo: «Tollat Crucem suam. Matth. 16, 24» (Lleve su cruz). Dice el epigrama: «Sua quique ferenda Crux, nulla eligenda» (Que cada uno ha de llevar su cruz sin elegir alguna). Se corresponde el epigrama con el título del capítulo II del Libro II de la Regia Via Crucis, en el cual está inspirada la escena (Fig. 14).

En los anteriores lienzos, inspirados en el libro I, Cristo ha mostrado a Staurofila la necesidad de recorrer el camino de la cruz para alcanzar la vida eterna; y la ha persuadido de que tome tan valiente decisión, poniendo el ejemplo de la Virgen y asegurándole que la sabiduría y justicia divinas proporcionan a cada hombre una cruz conforme a sus fuerzas. Por contra, mayor número y más pesadas cruces tendrán que arrastrar quienes traten de alejarse de la senda verdadera para disfrutar de las riquezas y honores. La anterior catequesis produce el deseado efecto en Staurofila, a quien contemplamos a comienzos del Libro II decidida a cargar con su cruz.

Por esta razón, Cristo la acompañó hasta una bella y espaciosa plaza, en la que yacían muchas cruces esparcidas por el suelo, todas ellas de diferente peso y tamaño, de manera que no había dos iguales. Ella se apresuró a escoger la más pequeña de todas, considerando que sus fuerzas no le permitirían cargar con una cruz mayor. Observando Cristo su actitud, reprende a la joven, significando que «no se da facultad aquí para que cada uno por su arbitrio elija la cruz, sino que conviene esperarla de mano de Dios». Uno no puede hacerse la cruz a su gusto y medida, procurando que no sea ni muy grande ni muy pesada, y tampoco puede dejarla en aquellas ocasiones en las que se encuentre cansado. Y le pone diversos ejemplos de quienes han recibido gustosamente la cruz que Dios les ha enviado, como San Francisco de Asís, San Francisco Javier o Santa Catalina de Siena, modelos a los que debemos tratar de imitar.

En el lienzo del convento aragonés observamos a Cristo y Staurofila en la frondosidad del bosque, entre cuya espesura se aprecia un templo; probablemente se trate de la capilla dedicada a la Santa Cruz que no había podido encontrar la muchacha, y que de manera simbólica alude al camino de la cruz. En el suelo, frente a la ermita, se encuentran varias cruces, una de las cuales se apresta a tomar Staurofila, si bien el Señor le indica con su mano otra de mayor tamaño. La escena principal apenas si sufre variaciones en el grabado y la pintura; pero no ocurre lo mismo con el fondo: en la estampa la acción se desarrolla en un marco arquitectónico, a la puerta de un templo y con otro dispuesto en segundo plano, del que se aprecia tan sólo una parte, mientras que en el lienzo los hechos transcurren en una masa boscosa densa y tupida, recortándose a contraluz sobre el cielo, que debemos poner en relación con el bosque cercano a su casa en el que se perdió Staurofila. A un lado se encuentra una iglesia de planta de cruz griega, uno de cuyos lados presenta una fachada con basamento, columnas y entablamento, sobre el que descansan estatuas. En la intersección de los brazos se eleva una cúpula con tambor circular articulado con ventanas, media naranja y linterna en el remate.

Las palabras de San Pablo a los Hebreos 12, 2: «Propossito sibi gaudio sustinuit crucem. Hebre 12» (En vez del gozo que se le proponía sufrió la cruz), constituyen el lema del sexto lienzo (Fig. 15). Significa el epigrama: «Spe mercedis crux toleranda» (Que se ha de tolerar la cruz con la esperanza del premio). La relación se establece en este caso con el capítulo XI del Libro II del tratado de Van Haeften (Fig. 16).

Camina ya Staurofila cargando con su cruz, compungida de haber merecido por sus culpas las penas del infierno, pero gozosa al mismo tiempo, de que podía redimirlas con esta mediana cruz. Viendo Cristo su cansancio y preocupación, quiso elevarla a cosas más altas: «Basta Staurofila de pisar esta senda, llena de tristezas, y temor, más amenos caminos te esperan, que has de correr, no sin gozo, y deleite. Dexado ya el temor, de aquí adelante mirarás al premio».

$A E A$, LXXVI, 2003, 302, pp. 133 a 152 


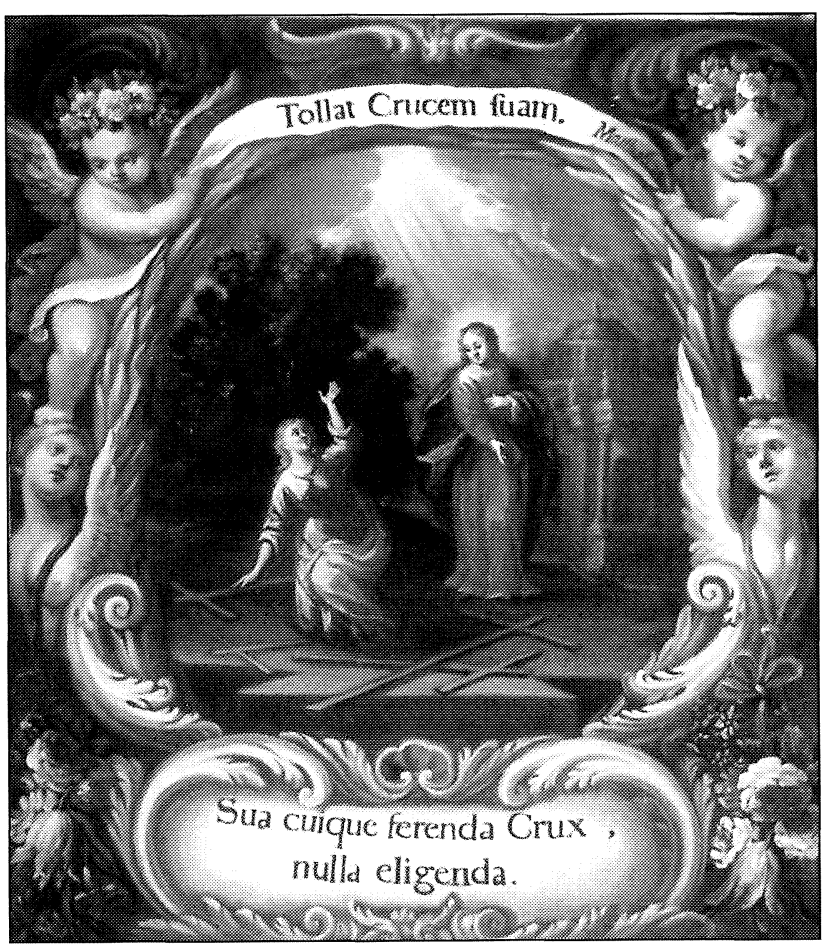

13
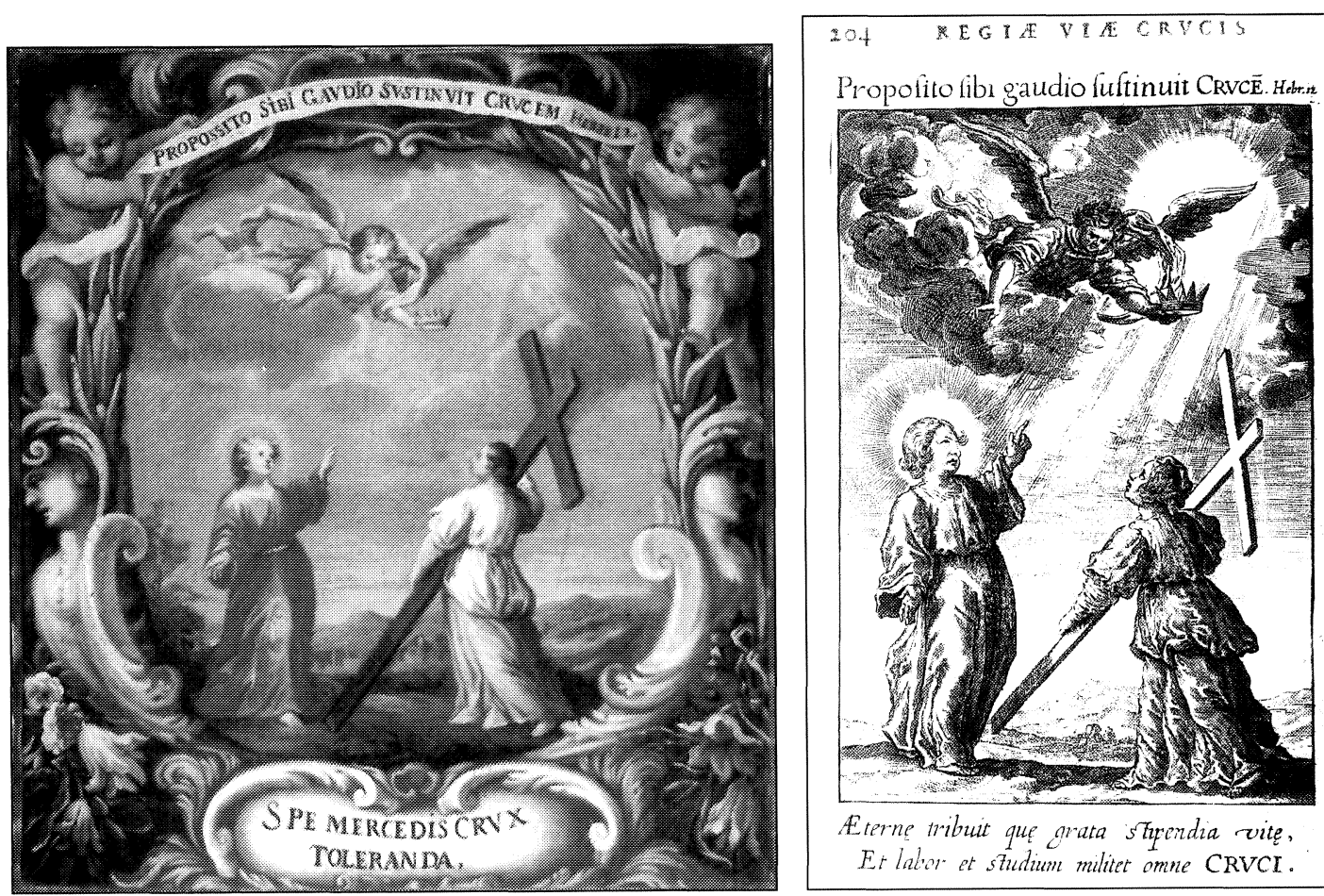

Eterne tribuit que grata stafondia vitę, Et laber et studium militet omne CRVCI.

15

Fig. 13. Quinto lienzo del Convento de Concepcionistas. (Foto. A. Aceldegui)

Fig. 14. Benedictus Van Haeften. Regia Via Crucis. Libro II, capítulo II.

Fig. 15. Sexto lienzo del Convento de Concepcionistas. (Foto. A. Aceldegui)

Fig. 16. Benedictus Van Haeften. Regia Via Crucis. Libro II, capítulo XI.

AEA, LXXVI, 2003, 302, pp. 133 a 152 
La muchacha se alegró al escuchar las palabras del Señor, quien continúa: «Si los oficiales, los labradores, y otros, sudan tanto por el jornal del día, y por un vil estipendio, como a cada paso lo notas, ¿qué no se debe trabajar por el premio de la vida eterna? Unidos están la Cruz, y el Reyno: ni conseguirá éste, el que no llevare aquélla. Si quieres reynar conmigo, lleva conmigo la Cruz. Sólo los siervos de la Cruz hallan la vida de la bienaventuranza, y de la luz verdadera». Desde este momento, Staurofila considera suave el trabajo y agradable la tribulación de llevar la cruz, pues tiene la certeza de que con ese corto precio se compra el Reino de los Cielos.

La pintura muestra nuevamente a Cristo y Staurofila, que lleva su cruz. Para que el cansancio no haga mella en ella, ni le entre la duda o la vacilación, Cristo considera que ha llegado el momento de mostrarle el premio que recibirá si persevera en su esfuerzo; por eso señala con su mano izquierda hacia el cielo, donde entre el resplandor divino aparece un ángel que porta la corona de la vida eterna. La escena, de menor complejidad que las anteriores, muestra un alto grado de identidad entre grabado y pintura, aunque en el caso de las ediciones españolas aparece nuevamente invertida.

El lienzo séptimo (Fig. 17) tiene por mote «Auxilium de tribulatione. Psal. 107, 13» (El auxilio de la tribulación), tomado del Libro de los Salmos. Y el epigrama significa: «Crux anchora spei, tessera salutis» (La Cruz es áncora de la Esperanza, y fuerte de la salud). La fuente grabada se encuentra en esta ocasión en el capítulo IV del Libro III (Fig. 18).

Se produce un cambio de escenario en el que hasta el momento venía desarrollándose la acción, dado que el paisaje salpicado de montes, valles y colinas, es sustituido ahora por el mar. El mar se convierte en imagen metafórica del mundo, «amargo por la sal, turbulento por las borrascas, alborotado por las tempestades, embravecido por las olas», nos dice San Agustín. Cristo pasea por la orilla, acompañado de Staurofila que camina a sus espaldas cargando con la cruz. De repente se desata un terrible vendaval que pilla por sorpresa a la joven y la arroja al agua, alejándola las olas de la ribera. Asustada Staurofila, solicitó la ayuda del Señor, a lo que Éste replicó: «iIgnoras acaso que la Cruz que traes te sirve de anchora con la qual aun en medio de las ondas, estés firme, y segura?». Con estas palabras la tranquilizó Cristo, a la vez que echando mano de la cruz la acercó a tierra firme, a la que regresó empapada y casi sin aliento.

De este suceso el Maestro extrajo una nueva lección que debía aprender Staurofila en su camino de la cruz: «No adviertes que estos, y otros accidentes, que pueden sucederte en el camino, te avisan a caminar con cautela por la senda de la cruz. El mundo no es sino un gran mar lleno de procelosas aguas, en el que acechan las grandes olas de los pecados y las tentaciones». Staurofila se asustó al comprender los peligros que la acechaban, y pensando que le resultaría imposible librarse de todos ellos, pidió a Cristo que le indicase la manera de enfrentarse a los mismos; a lo que Éste replicó con las palabras de San Pablo a los Hebreos: «Tenemos un fortísimo consuelo los que nos acogemos a asirnos de la esperanza que se nos propone: la qual nos sirve como de segura, y firme anchora del alma» ${ }^{30}$. La enseñanza de Jesús es clara: la cruz es la mejor ancla para mantener firme nuestra esperanza contra las tentaciones de esta peregrinación. Staurofila supo comprenderla, y rogó al Señor que, evitando los escollos del mar enfurecido, pudiera navegar siguiendo el rumbo correcto y arribar a puerto seguro.

En el lienzo del convento aragonés vemos el mar surcado por navíos de diferentes tamaños con sus velas, banderolas y gallardetes al viento; a la derecha, al cobijo de una montaña,

\footnotetext{
${ }^{30}$ Tomado de la Epístola de San Pablo a los Hebreos, cap. 6, v. 18. También San Agustín alude a la cruz para evitar el naufragio en el comentario al salmo 51: «Sálvate, si puedes, del sumergimiento. ¡Pretendes evitar el naufragio y te abrazas a una plancha de plomo! Si no quieres sumergirte, abrázate a una tabla. Te soporte el madero; te guíe la cruz». Obras de San Agustín, Tomo XX, Madrid, Biblioteca de Autores Cristianos, 1965, pág. 285.
}

$A E A$, LXXVI, 2003, 302, pp. 133 a 152 

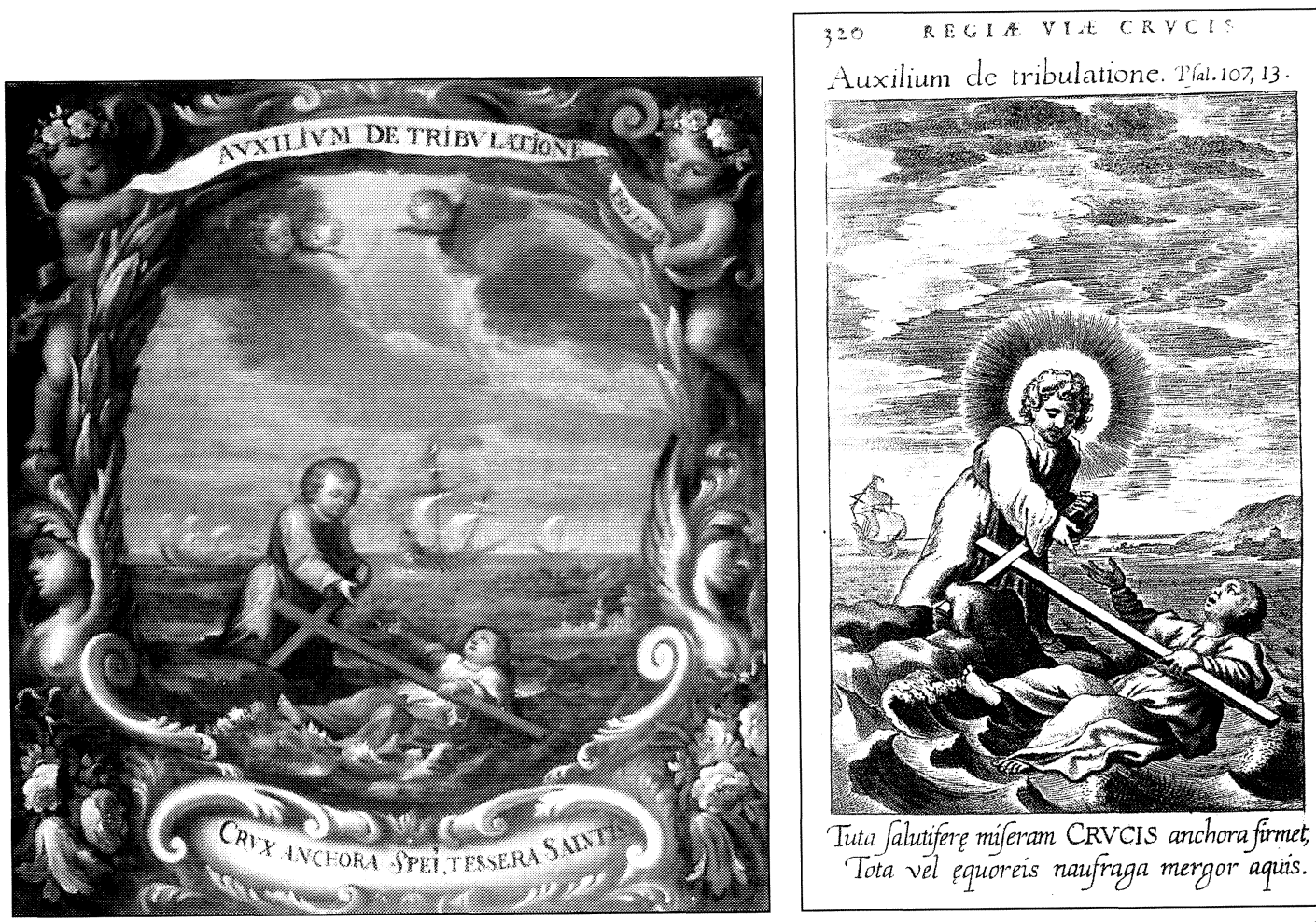

Tuta falutiferę miferam CRVCIS anchora firmet, Tota vel equoreis naufraga mergor aquis.

17
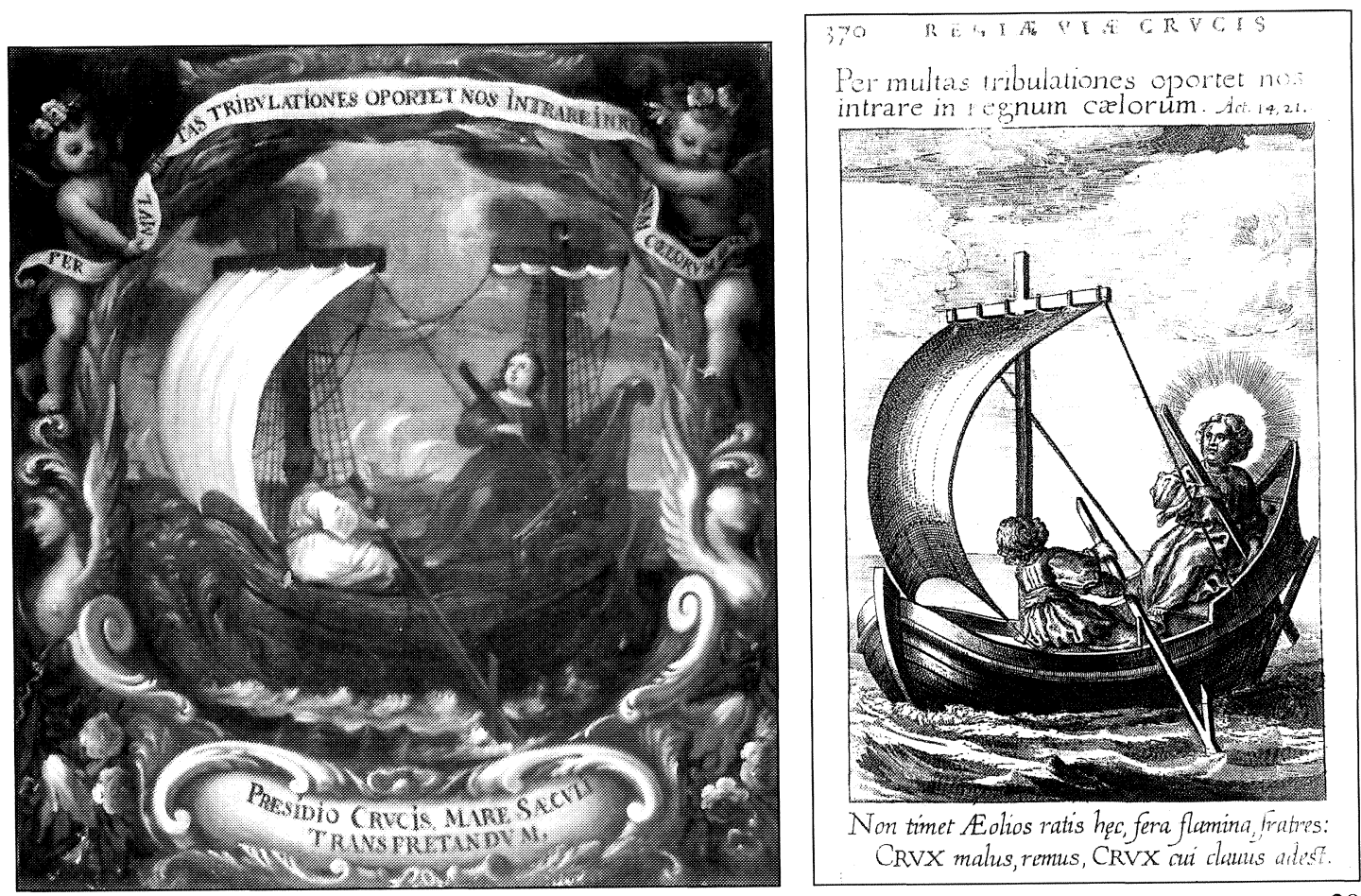

19

Fig. 17. Séptimo lienzo del Convento de Concepcionistas. (Foto. A. Aceldegui).

Fig. 18. Benedictus Van Haeften. Regia Via Crucis. Libro III, capítulo IV.

Fig. 19. Octavo lienzo del Convento de Concepcionistas. (Foto. A. Aceldegui)

Fig. 20. Benedictus Van Haeften. Regia Via Crucis. Libro III, capítulo X.

AEA, LXXVI, 2003, 302, pp. 133 a 152 
se divisa una ciudad con sus edificios y torres. En la orilla, Cristo tiende su mano a Staurofila, que ha caído al agua y se sujeta con fuerza a la cruz que hace las veces de ancla. La imagen del ancla en relación con la Esperanza es tradicional, y ya se encuentra en San Agustín en su comentario al Salmo 64. También la mantiene Ripa en su Iconología. La pintura nos indica por tanto que la Esperanza se convierte en virtud imprescindible para el progreso de nuestra vida espiritual. Personajes y actitudes son idénticos en el grabado y en el lienzo, pero en este último la amplitud espacial es mayor y el fondo marítimo aparece más desarrollado, con tres navíos en vez del único de la estampa; en el de mayor tamaño, situado en el centro de la composición, se aprecia el remar de la tripulación. Además, en el cielo se abre un resplandor que deja ver tres querubines inexistentes en la fuente gráfica.

El programa iconográfico se cierra con el octavo lienzo (Fig. 19), cuyo lema está tomado de los Hechos de los Apóstoles: «Per multas tribulationes oportet nos intrare in regnum coelorum. Act. 14, 21» (Por medio de muchas tribulaciones nos conviene entrar en el Reino de los Cielos) ${ }^{31}$. Dice el epigrama: «Praesidio Crucis, mare saeculi transfretandum» (Que se ha de navegar en el mar del mundo con el presidio de la Cruz). El capítulo X del Libro III de la Regia Via Crucis, se ilustra con el grabado que inspira el lienzo (Fig. 20).

Después de haber caminado largo tiempo Staurofila por el camino de la Cruz, se acercaba ya al término del trayecto, y de la vida; por eso la hizo Cristo subir en una embarcación, para que navegando por las peligrosas aguas de este mundo, arribasen al puerto de la patria celestial, diciéndole: «lo que falta del camino lo acabarás con más conveniencia conmigo en esta nave, porque no estás lexos de la patria, y del fin tantas veces deseado».

Staurofila accede gustosa a la invitación del Señor. Y nada más embarcar se percata con asombro de que es la cruz la que. dirigirá el rumbo de la nave y la hará avanzar por el mar de este siglo para llegar a la vida eterna; así, el ancla tiene forma de cruz, al igual que los remos, el timón y el mástil en el que se hinchan las velas, tal y como refiere la muchacha en voz alta: «Pero quantas cosas, que apenas me acuerdo haber considerado antes, contemplo aquí que traen a los ojos del cuerpo, y del alma el misterio de la Cruz. Porque qué otra cosa es la ancora, que una duplicada Cruz? También se registra naturalmente esta señal sagrada en la nave, quando hinchadas las velas navega, quando estendidos los remos se desliga. La mar no se corta, si este trofeo, que llaman mastil, no está entero en el navío. Pues ya el timón quanto discuerda de la Cruz».

Conocido es que la imagen de la nave en relación con la Iglesia fue símbolo frecuente en el barroco. En este sentido, Cristo realiza una completa descripción de la nave mística en la que navega Staurofila hacia la Celestial Jerusalén, que Van Haeften toma del comentario de San Agustín al Salmo 51. Staurofila pregunta si esta nave formada con las tablas de la paciencia entrará en el puerto deseado, a lo que Cristo responde afirmativamente: «Entra, y a la verdad prontísima, y segurísimamente. No hay que dudar en esto, porque si te acuerdas de que por medio de muchas tribulaciones conviene entrar en el Reyno de los Cielos; advertirás que con la nave de la Cruz se han de cortar las aguas de las tribulaciones, y caminar así al puerto de la gloria».

En el lienzo, Cristo y Staurofila se encuentran a bordo de un barco que navega sobre un mar tempestuoso; el Señor dirige el rumbo mientras la muchacha rema. Tanto el remo como el timón, y los mástiles a los que se sujetan las velas, una de ellas hinchada por el viento, tienen forma de cruz. La pintura aragonesa resulta mucho más elegante que su fuente grabada, tanto por el diseño del casco de la nave con sus motivos decorativos en proa y popa, sus dos mástiles bien pertrechados, o el paisaje de fondo en el que se aprecian otros navíos.

${ }^{31}$ En realidad la cita no procede del versículo 21 , sino del 22.

$A E A$, LXXVI, 2003, 302, pp. 133 a 152 


\section{Presencia del programa en el convento de Miedes}

El estudio del programa iconográfico del convento aragonés nos permite realizar una doble reflexión. En primer lugar, la selección de los temas representados no resulta casual, sino que se encuentra perfectamente meditada. De las treinta y seis posibles, las ocho estampas escogidas para plasmar en lienzo constituyen una síntesis perfecta de la doctrina contenida en la Regia Via Crucis, máxime si se tiene presente el ámbito para el que estaba destinado, un convento de clausura femenino. El programa se inicia con el Señor que muestra el estrecho y escarpado Camino de la Cruz como senda a seguir para alcanzar la vida eterna, que para las religiosas se convierte en el abandono del mundo. Ante tal exigencia pueden surgir dudas o vacilaciones que lleven a la tentación de rehusar andarlo, pero Cristo las ilumina para seguir en él, poniendo como ejemplo a su Madre la Virgen, quien llevó la cruz con constancia y fortaleza. A ello debe unirse la confianza en la sabiduría y justicia de Dios, que concede a cada cual la cruz del tamaño que puede soportar para que ni le oprima ni le haga caer; además, no hay que medir la cruz por su peso externo o por las fuerzas de cada uno, sino por la fuerza de la gracia y el auxilio divino. Por el contrario, aquéllos que se aparten del camino del sacrificio, la humildad y la mortificación, y opten por el de los honores, los placeres y las riquezas, tendrán que cargar con una cruz todavía más pesada que les impondrá el demonio. En consecuencia, cada religiosa ha tomar la cruz que Dios le conceda, sin elegir la que a su juicio resulte más cómoda de llevar; y cargarla con la alegría y la esperanza del que sabe que será premiado con la corona de la gloria. Por supuesto que el camino no será fácil, y se verá plagado de peligros y tribulaciones que pueden hacer caer en el mar del pecado y las tentaciones; pero todas ellas se solventarán con mayor facilidad cuanto más sólida sea la fe y más se aferre uno al madero de la cruz, que se convertirá así en firme ancla y en el mejor aliado. Y finalmente, tras una vida virtuosa y llena de esperanza, llegará el momento de navegar dichoso junto a Cristo hacia el seguro puerto de la eternidad.

La presencia de un programa de estas características resulta coherente en un convento de clausura femenino; pero dicha coherencia resulta todavía mayor en el caso del convento de Concepcionistas de Miedes, en el que el tema de la cruz gozaba de un protagonismo incuestionable. Así se desprende de la biografía de la madre sor Inés de Jesús y Franco, escrita en 1733 por don Diego Franco de Villalba, capellán del convento, miembro del Consejo de Su Majestad, y Oidor en la Real Audiencia de Aragón ${ }^{32}$. Sor Inés había nacido el día de Viernes Santo de 1630 en Acered, pueblo de la comunidad y partido de Calatayud. En 1644 ingresó en el convento de Miedes, en el que falleció el 21 de junio de 1677, tras una vida llena de sufrimiento consagrada por entero al Señor; treinta y tres años permaneció la religiosa en los muros de la clausura, los mismos que vivió Cristo. Según relata su biógrafo, en una ocasión se le apareció la Virgen y le entregó una cruz de madera, que se convirtió en una preciada reliquia y realizó innumerables curaciones milagrosas una vez muerta la religiosa, tanto dentro como fuera del convento; así lo recoge don Diego:

«Hay en el convento una cruz de madera que parece ser de manzano, y se conoce haver sido en su forma, de Carabaca. La qual para en poder de la M. Josepha de San Miguel y Gómez de Bernabé, actual abadesa, quien hallándose gravemente enferma, curó de la dolencia a influjo de la sagrada reliquia. Y se pide muchas veces para dentro y fuera, por la devoción que se le tenía. Y esta Cruz, se entiende, y comunmente dize, que se la dio Nuestra Señora a la Venerable Madre Inés de Jesús y Franco... Después de muerta la Venerable Madre, ha mani-

${ }^{32}$ La Heroyna Religiosa Sor Inés de Jesús y Franco. Cuya vida exemplar, y esclarecidas Virtudes, describe, y publica, el Dr. D. Diego Franco de Villalba, Presbytero, de el Consejo de Su Majestad, Oydor en la Real Audiencia de Aragón, que reside en Zaragoza. Con licencia: En la Imprenta de Francisco Revilla, en la Calle de San Lorenzo, Año 1733. 
festado también la experiencia muchas vezes, su especial virtud, y milagroso remedio... A una muger en Orera, endemoniada, llevando la cruz y estando en el camino, les dixeron los de Orera que ya gritaban los demonios: Ya viene la Cruz, vamos fuera» ${ }^{33}$.

La fama de la cruz del Convento de la Purísima Concepción y San Blas de Miedes se extendió por toda la comunidad, y numerosas personas sanaron de sus dolencias merced a su presencia. En consecuencia, la devoción a la cruz arraigó hondamente entre las religiosas del convento, como demuestra el hecho de que al ingresar en clausura muchas de ellas incorporaban a su nombre el apelativo «de la Cruz»o «de Cristo Crucificado». Es más, la referencia a la cruz se encuentra presente en diversos informes y memoriales redactados por las madres abadesas a lo largo de los siglos, pudiendo leerse expresiones como «el alibio de mi cruz que por tantos títulos me es tan pesada» ${ }^{34}$. Quizás sea ésta la razón fundamental que justifique la presencia en el monasterio del programa iconográfico inspirado en la Regia Via Crucis de Benedicto Van Haeften. De hecho, resulta significativa la proximidad cronológica existente entre el año 1677 en que fallece la madre Inés de Jesús y Franco, y la fecha de ejecución de los lienzos, que hemos datado en el último tercio del siglo XVII.

\footnotetext{
${ }^{33}$ Ibídem, fols. 184-85.

${ }^{34}$ Esta expresión emplea la abadesa sor Gracia María de la Asunción en carta dirigida al obispo de Tarazona fray García Pardiñas Villar de Francos y fechada el 12 de febrero de 1729, en la que participa al prelado de las disensiones surgidas en el seno de la comunidad religiosa. Archivo Histórico Diocesano de Tarazona. Religiosas Concepcionistas de Miedes (1695-
} 1890). 